\title{
Mudanças no Estado-avaliador: comparativismo internacional e teoria da modernização revisitada
}

\author{
ALMERINDO JANELA AFONSO \\ Universidade do Minho
}

As abordagens ao campo da avaliação educacional têm sido múltiplas e heterogêneas: quer em termos de olhares disciplinares ou interdisciplinares; quer em termos de políticas, teorias, metodologias, modelos ou dispositivos; quer em termos de complexidade, confronto e/ou interação entre dimensões e funções envolvidas; quer, ainda, em termos de dominâncias ou focalizações (mais normativas e prescritivas ou, ao contrário, mais descritivas e compreensivas).

Em qualquer dos casos, o olhar sociologicamente informado sobre o campo da avaliação não tem, nesse conjunto de contributos e abordagens, nenhum privilégio ou precedência. Mesmo assim, a mobilização de certos conceitos e teorias não deixará de configurar especificidades analíticas, mais ou menos fragmentárias, a partir das quais os exercícios de argumentação procurarão os sentidos (sociológicos) escondidos na empiria, isto é, nos dados e fatos concretos que traduzem uma determinada realidade social e educacional (institucional, local, nacional, regional ou global).

Depois de rever algumas características da primeira fase do Estado-avaliador, o exercício exploratório delineado neste texto revisita a (velha) teoria da modernização para, em seguida, sugerir que alguns dos seus pressupostos continuam, em grande medida, subjacentes ao atual comparativismo avaliador - agenda política crescentemente dominante, pelo menos, desde os finais dos anos de 1990, e à qual corresponde o que designo de segunda fase (ou reconfiguração) do Estado-avaliador. $\mathrm{O}$ artigo procura também levantar algumas questões e hipóteses em torno de uma terceira fase (a fase pós-Estado-avaliador), a qual, apresentando ainda contornos pouco definidos, pode vir 
a inscrever-se, com crescente evidência, na continuidade da expansão global capitalista das políticas de privatização e mercadorização da educação (e da avaliação).

\section{A(S) TEORIA(S) DA MODERNIZAÇÃO: BREVES APONTAMENTOS}

Na perspectiva de Göran Therborn (2000), a modernização é um conjunto difuso de discursos sobre mudança social que está longe de se constituir como um paradigma ou sequer como uma teoria consensual. ${ }^{1}$ No entanto, apesar de, não raras vezes, diferentes autores porem em causa a capacidade hermenêutica da teoria da modernização, não deixam, todavia, de reconhecer que ela teve sempre alguma importância, mais discreta ou mais marcante, no âmbito das ciências sociais, estando muito presentes na literatura especializada as remissões para autores funcionalistas, como Émile Durkheim e, sobretudo, Talcott Parsons, na qual é possível, também nesta questão, encontrar sugestivas âncoras conceptuais (Cardoso, 2005; Machado, 1970; Schmidt, 2011).

Para Mike Featherstone (2000), a teoria da modernização refere-se a diferentes estágios de desenvolvimento social que, entre outros aspetos, baseiam-se na industrialização, no incremento da ciência e da tecnologia, na urbanização, na criação de infraestruturas e no acesso a um mercado capitalista mundial. A modernização é um dos sentidos possíveis inerentes à própria ideia de modernidade (idem, p. 28). Aliás, quando se pensa a mudança social, tendo como referência, por exemplo, o debate entre modernidade e "modernidades múltiplas" (Eisenstadt, 2001), é frequente surgirem alusões ou argumentações mais ou menos demoradas sobre a teoria da modernização. ${ }^{2}$

Também em diferentes conjunturas históricas, a teoria da modernização tem sido convocada para explicar os processos de desenvolvimento versus subdesenvolvimento (em contextos pós-coloniais, sobretudo na Ásia, África e América Latina), mas também para dar sentido às mudanças sociais após a $2^{\mathrm{a}}$ Guerra Mundial, na Europa, ou, mais recentemente, para justificar o suposto fim da história, enquanto redirecionamento inevitável em relação ao modelo de desenvolvimento de países mais avançados, como os EUA. São estes, aliás, que aparecem como novo paradigma, por um lado, em consequência do fracasso e colapso do socialismo real e, por outro, enquanto protagonistas da consolidação do capitalismo demoliberal como sistema econômico hegemônico.

Sobre este último aspeto, aliás, como chamam a atenção vários autores, embora haja análises que situam a sua gênese em períodos históricos muito anteriores, a teoria da modernização, depois de predominar nos anos de 1950 e 1960, foi objeto de muitas críticas,

1 "A modernização é um conjunto de discursos sobre a mudança social. A modernização não é um paradigma, qualquer que seja o sentido que aquele possa ter; e só ocasionalmente é usada com o mínimo de consistência para justificar o epíteto de teoria. Não há consenso quanto ao que possa constituir o cânone da teoria da modernização. Pelo contrário, é um conjunto difuso de discursos sobre a mudança social" (Therborn, 2000, p. 49-50, tradução minha).

2 Usarei a expressão teoria da modernização, em vez de teorias da modernização, porque, embora reconheça que há diferentes teorias que procuram explicar sentidos diferentes dos processos de modernização e de desenvolvimento, todas elas partilham alguns pressupostos (e são estes que me interessa sublinhar ao usar a expressão no singular). 
passou por um período de breve ostracismo, mas, já nos anos de 1980, deu sinais de "um certo renascimento", em grande parte motivado, justamente, pelo colapso da experiência do chamado socialismo real (Inglehart; Welzer, 2006).

Ainda que a teoria da modernização enfatize as dimensões econômicas e políticas, não desconhece a importância de outras, como a educacional, sobretudo quando, entre outros aspetos, acentua a expansão mundial, tendencialmente isomórfica, de projetos muito dependentes da criação e consolidação dos Estados-nação, como é o caso da "disseminação da escolarização em massa” (Schmidt, 2011,p. 160). Sobre este propósito, ainda que sejam perspectivas voltadas para distintos objetos, há certamente interfaces que podem ser discutidas confrontando postulados da teoria da modernização com postulados de uma cultura educacional mundial comum que, neste último caso, autores institucionalistas como John Meyer defendem há várias décadas. ${ }^{3}$ De acordo com Roger Dale (2004,p. 426-427),

O argumento central dos institucionalistas mundiais é que as instituições do estado-nação, e o próprio estado, devem ser vistos como sendo essencialmente moldados a um nível supranacional através de uma ideologia do mundo dominante (ou Ocidente), e não como criações nacionais autónomas e únicas. Sob esta perspectiva, os estados têm a sua actividade e as suas políticas moldadas por normas e cultura universais.

Considerando estes e outros argumentos, e uma vez que as questões educacionais não são indiferentes à teoria da modernização, parecerá menos estranho retomar aqui esta teoria (por muitos julgada anacrônica), ainda que sinalizando um ou outro dos seus défices explicativos, para, em seguida, introduzir um olhar exploratório sobre a questão das avaliações internacionais comparadas, relativas ao desempenho escolar dos alunos de diferentes sistemas educativos nacionais.

Entretanto, o que aqui pretendo acentuar não é tanto a capacidade de explicação, supostamente científica, da teoria da modernização, mas antes a sua dimensão ideológica. ${ }^{4}$ $\mathrm{E}$ isto, do meu ponto de vista, parece fazer mais sentido dado ser possível constatar, com alguma frequência, a coexistência (não conscientizada ou não problematizada) entre a escassa ou nula capacidade hermenêutica de uma teoria pretensamente científica e o seu vigor e reatualização como ideologia.

Como refere Miriam L. Cardoso (2005, p. 2):

Boa parte da importância que as teorias da modernização conseguiram está relacionada com a cientificidade e o rigor pretendidos pelas suas formulações. Cabe supor, no entanto, que sua importância decorre sobretudo do significado político de que a modernização se revestiu ao se propor enquanto ideologia e enquanto engenharia social a serviço da identidade nacional, do governo norte-americano e do capital em expansão.

3 Para uma análise bastante desenvolvida sobre algumas destas questões, ver Joaquim Azevedo (2007).

4 Uma exposição muito esclarecedora sobre o conceito de ideologia, como "ideário histórico, social e político que oculta a realidade", pode ser encontrada em Marilena Chauí (2001, p. 7). 
Em termos muito breves, como lembra Piotr Sztompka (2005), a modernização pode ter três acepções distintas: i) ser, em qualquer período da evolução das sociedades, "sinónimo de mudança social progressiva"; ii) ser uma forma de enunciar as transformações inerentes (ou em direção) à modernidade; iii) ser referenciada, de forma restrita, aos "esforços para alcançar os países avançados ou mais desenvolvidos", sublinhando, no mesmo momento histórico,"o movimento das periferias em direção ao centro da sociedade moderna" (idem, p. 227-228).

A teoria da modernização, de acordo com Sztompka, tende a circunscrever-se a esta última acepção e, em tal sentido - na sua formulação original posteriormente criticada por diversos autores (Schmidt, 2011; Therborn, 2000; Wallerstein, 2004) -, o que está subjacente é uma concepção evolutiva e unilinear da mudança social. Isto pressupõe que as sociedades menos desenvolvidas devem galgar as mesmas etapas que outras sociedades tiveram de percorrer anteriormente, sendo este, muitas vezes, o sentido assumido por algumas elites nacionais ou grupos dominantes que encaram o desenvolvimento tendo como padrão de referência as sociedades capitalistas mais avançadas. Não se trata, portanto, de um desenvolvimento espontâneo ou natural, mas de um processo que se deseja frequentemente acelerado de "emulação intencional de standards" e de uma "imitação deliberada” (Sztompka, 2005, p. 230-232).

É justamente o fato de a teoria da modernização acentuar a convergência no âmbito do projeto de modernidade, supostamente otimista e unidirecional, que suscita fortes reações, sobretudo por parte de autores que consideram que não há uma modernidade, mas sentidos evolutivos e plurais de modernidade, os quais são, frequentemente, conflituais e contraditórios. Por isso, a modernização não caminha de modo inexorável para o fim da história, enquanto suposto consenso em torno de um determinado modelo social, econômico e político. ${ }^{5} \mathrm{E}$, de igual modo, também não se trata do retorno definitivo a uma concepção hegemônica de modernidade. Muito pelo contrário,

Não só continuam a emergir modernidades múltiplas - indo, hoje em dia, para além das premissas do estado-nação - como surgem igualmente novos modos de questionar e reinterpretar as diferentes dimensões da modernidade no seio de todas as sociedades. É inegável a tendência, no final do século XX, para a crescente diversificação dos modos de compreensão da modernidade, dos programas culturais básicos de diferentes sociedades modernas - muito para além das visões homogéneas e hegemónicas da modernidade que prevaleciam na década de 50. [...] Todos estes desenvolvimentos atestam, de facto, o contínuo desenvolvimento de modernidades múltiplas, ou de múltiplas interpretações da modernidade - e, sobretudo, atestam as tentativas de "desocidentalização", privando o ocidente do seu monopólio sobre a modernidade. (Eisenstadt, 2001, p. 157-158)

O confronto com as críticas que surgem de diferentes lugares e autorias talvez tenha revigorado, de algum modo, os pressupostos da teoria da modernização, passando

5 Como diz Ulrich Beck (1998,p. 238, grifos do original), "El progreso sustituye el consenso. Todavía más: el progreso es un sustituto del cuestionamiento, una especie de previa aceptación de fines y consecuencias que ni se conocen ni se mencionan". 
esta a reconhecer algo de semelhante ao que a teoria das modernidades múltiplas tem acentuado. Com efeito, a teoria das modernidades múltiplas afirma "que ocorrem presentemente mudanças significativas e duradouras na posição relativa e na influência detida pelos diferentes centros de modernidade - oscilando entre o ocidente e o oriente" (idem,p. 153) e a teoria da modernização reconhece a existência de "epicentros móveis de modernidade" (Sztompka, 2005, p. 242). Num certo sentido, depois de revista em alguns dos seus pressupostos iniciais, a (agora) designada teoria da neomodernização não deixa de valorizar as condicionantes decorrentes das alterações nas relações mundiais, assumindo, desde logo, que os países de referência não têm de ser sempre, ou necessariamente, os mesmos. Neste sentido, como assinala ainda Sztompka (idem, p. 244), a teoria da neomodernização resulta em grande medida do fato de a anterior ter sido "expurgada de todas as implicações evolucionistas e desenvolvimentistas", adquirindo, conjunturalmente, outras possibilidades de interpretação das mudanças sociais.

\section{A PRIMEIRA FASE DO ESTADO-AVALIADOR}

A emergência da última grande vaga avaliadora - que ocorreu, inicialmente, em países capitalistas centrais (como os EUA e a Inglaterra) e estendeu-se, ao longo dos anos de 1980, para uma grande parte de outros países situados em lugares distintos do sistema mundial - tem sido compreendida, na minha perspectiva,como parte de mudanças sociais, políticas e culturais mais amplas, desencadeadas nesse período histórico, nomeadamente, pela viragem neoconservadora e neoliberal (Afonso, 1998, 1999).

Todavia, o que se apresenta como relativamente consensual é o fato de a avaliação constituir, a partir desse momento, um dos eixos estruturantes das reformas da administração pública e de formas de governo reinventadas (ver, a este propósito, Al Gore, 1994; Osborne; Gaebler, 1992) - razão pela qual a expressão Estado-avaliador, inicialmente proposta para chamar a atenção para as mudanças no ensino superior (Neave, 1988), passou a ser usada e convocada tendo em mente muitos outros domínios das políticas públicas e educativas.

Gostaria de sugerir, em termos genéricos, que essa foi a primeira fase ou versão do Estado-avaliador, sendo relativamente distinta da que veio a seguir (embora todas as fases coexistam ou possam coexistir atualmente). Assim, nesta primeira fase, a adoção de políticas de avaliaçãoo (incluindo a avaliação em larga escala no interior de um mesmo país) dependeu, em grande medida, de uma (ainda) expressiva autonomia relativa dos Estados nacionais ou, mesmo, da autonomia relativa de Estados enquanto unidades de uma Federação (como no caso brasileiro). ${ }^{6}$

Nos países que iniciaram, há mais de duas décadas atrás, a vaga de reformas neoliberais e neoconservadoras, a avaliação constitui-se ela própria como uma política estatal, enquanto instrumento da ação dos Estados e governos, tendo muito a ver com

6 Para alguns estudos e reflexões recentes sobre avaliação em larga escala em contexto estadual, claramente inseridos, do meu ponto de vista, nas avaliações típicas da primeira fase do Estado-avaliador, ver, por exemplo, Martins e Zákia (2012); Schneider et al. (2011); Zákia e Arcas (2010); Zákia e Oliveira (2010). 
leituras internas das especificidades nacionais, ainda que filtradas e interpretadas por novas orientações ideológicas então emergentes - nas quais, em certos casos, os aspectos simbólicos foram ampliados (e dramatizados) por oposição a outras realidades nacionais.

Foi assim que se justificou, por exemplo, no início dos anos de 1980, a famosa reforma conservadora $A$ Nation at Risk, já que a competitividade econômica e a inovação tecnológica dos EUA se davam como fortemente ameaçadas pelo fato de as performances dos alunos serem, em muitos casos, inferiores às de alunos de outros países capitalistas menos desenvolvidos (ou, em alguns casos, países diretamente concorrentes na disputa pela hegemonia mundial, como ainda era o caso, na altura, da União Soviética). Nos EUA, sob a liderança de Reagan, as soluções propostas passaram, entre muitos outros aspectos, por um aumento do controle da educação pública por parte do Estado, pelo retorno à autoridade e centralidade dos professores (com o consequente menosprezo pelas pedagogias construtivistas e não diretivas assentes no protagonismo discente), pela revalorização de disciplinas consideradas básicas ou fundamentais nos currículos (back to basics), pela introdução de critérios de maior rigor, seletividade e meritocracia, e pela dominância de lógicas de competição, de escolha parental e de mercado educacional tendentes a esbater (ou mesmo acabar com) o monopólio da educação pública estatal. Ressalvando as especificidades nacionais, foi assim também no caso da Inglaterra, nomeadamente com a alteração nas condições do exercício da autonomia profissional dos professores, com a introdução de um currículo nacional e com a adoção de exames nacionais em decorrência da reforma thatcheriana (Education Reform Act 1988).

Em ambos os casos, assinale-se, ainda não tinha caído o muro de Berlim, os efeitos da globalização ainda não eram muito evidentes, e não estávamos imersos num processo de tão clara expansão e internacionalização do capitalismo, como o que se seguiu à crescente hegemonia dos EUA pós-guerra fria. Assim, no contexto imediatamente anterior à assunção generalizada do fracasso do socialismo real, a primeira fase do Estado-avaliador foi claramente conotada, em termos político-ideológicos, com o neoconservadorismo e o neoliberalismo emergentes, sendo igualmente a expressão de uma agenda (já) marcadamente preocupada com a afirmação e manutenção, mais explícitas, da supremacia educacional de alguns países face a outros, reforçando (internamente) a identidade nacional e (externamente) a procura de vantagens competitivas, num mundo em que o processo de globalização se iria tornar crescentemente perceptível.

$\mathrm{Na}$ sequência de políticas avaliativas estreitamente articuladas com o exercício do controle social por parte do Estado, pode igualmente ser referenciada à primeira fase do Estado-avaliador a introdução de mecanismos de accountability baseados em testes estandardizados de alto impacto e em rankings escolares, indutores de formas autoritárias de prestação de contas e de responsabilização das instituições, organizações e indivíduos, como tem sido o caso do programa No Child Left Behind (Afonso, 2009).

Iniciado nos EUA na era de George W. Bush, esse programa acabou por se transformar, pelas piores razões, num caso verdadeiramente representativo do viés político-ideológico da nova direita. Embora muitas destas questões sejam recorrentes em diferentes conjunturas, o fato é que esta última reforma neoconservadora favoreceu um forte intervencionismo do Estado central, paradoxalmente, num sistema educativo amplamente descentralizado (Normand, 2008), e expandiu muito o regime de sanções negativas contra os professores e as escolas públicas. Para além dos EUA (Ravitch, 2011), 
as políticas de accountability baseadas em resultados escolares, e assumindo um cariz mais coercitivo e negativamente sancionatório, têm vindo igualmente a verificar-se em muitos outros países (Afonso, 2009, 2012).

Ressalve-se, todavia, que a recepção destas agendas avaliativas não foi (nem é) indiferente às especificidades dos diferentes países no sistema mundial, nomeadamente no que diz respeito aos países periféricos e semiperiféricos.

Na linha de alguns trabalhos de João Barroso (2003a, 2003b), é importante considerar que, mesmo admitindo a hipótese do efeito de contaminação, fruto da ação de fóruns e organizações internacionais, como o Banco Mundial e a Organização para a Cooperação e Desenvolvimento Econômico $(\mathrm{OCDE})^{7}$ e, em geral, como consequência do próprio processo de globalização e dos novos modos de regulação nacionais e internacionais, a transferência (ou empréstimo) de políticas de uns países para outros (ou o que certos autores designam de educational policy borrowing), nunca ocorre, na minha perspectiva, nem de forma sincrônica nem de forma mimética, justamente pelo fato de os diferentes países estarem em diferentes lugares no sistema mundial, e terem especificidades sociais, culturais, históricas, políticas, econômicas e educacionais que implicam, na maioria das vezes, processos de recontextualização ou mesmo de resistência por parte dos Estados nacionais. ${ }^{8}$

Para além dos mecanismos de empréstimo e de aprendizagem de politicas que, aliás, Roger Dale (2007) referencia como os mais tradicionais e anteriores ao processo de globalização, mas que poderão ser reconfigurados neste novo contexto, tal autor distingue ainda outros mecanismos mais recentes de transferência de políticas, os quais estão mais relacionados com os efeitos (indiretos) da globalização (barmonização, disseminação, estandardização, instalação de interdependência e imposição).

Considerando a hipótese de uma globalização de baixa intensidade no campo da educação, pelo fato de existir uma "mediação obrigatória dos Estados nacionais na formulação das respectivas políticas" (Teodoro, 2001, p. 152), penso que essa globalização de baixa intensidade corresponde melhor à primeira fase do Estado-avaliador. Neste sentido, sendo certo que, sobretudo, no caso dos países periféricos e semiperiféricos no contexto mundial, há muito tempo as organizações internacionais, como a Organização das Nações Unidas para a Educação, a Ciência e a Cultura (UNESCO), o Banco Mundial e a OCDE, entre outras, interferem (direta ou indiretamente) nas agendas educativas

7 Pelo menos na última década e meia, entre os autores portugueses que mais têm estudado o papel das organizações internacionais e seu impacto na educação, devo salientar os trabalhos de António Teodoro $(2001,2003,2005)$. Para o caso mais específico da União Europeia como organização supranacional, ver, entre outros, Fátima Antunes (2008) e António Nóvoa (2010).

8 Tal como pude sublinhar noutro texto, "Apesar da preocupação sociológica com a demonstração das especificidades nacionais - atitude que [...] não deixa, por isso, de permitir a descoberta de espaços de ambiguidade e até de estratégias de resistência na configuração das políticas nacionais, que podem vir a ser aproveitados para contrariar os efeitos da retórica ideológica neoliberal - há, obviamente, aqueles arautos da globalização, na versão homogeneização cultural ou mcdonaldização da sociedade, a que se juntam os pessimistas ou descrentes em relação às possibilidades da globalização contra-hegemónica, que não se cansam de anunciar, também aqui, a inevitável convergência global de todos os sistemas educativos" (Afonso, 2003, p. 42). 
nacionais, nomeadamente ajudando a legitimá-las ou disponibilizando-lhes assistência técnica, a sua presença, todavia, no período correspondente ao que designei de primeira fase do Estado-avaliador, é, apesar de tudo, relativamente discreta e não tão explicitamente vinculante para a definição das políticas educativas nacionais como acontece, bem ao contrário, na segunda fase (ou reconfiguração) do Estado-avaliador.

$\mathrm{Na}$ minha perspectiva, nessa segunda fase, o Estado-avaliador passa a ser confrontado de forma mais clara com os efeitos externos sobre as políticas educativas, que já não têm origem, essencialmente, nos mecanismos tradicionais (como o empréstimo ou aprendizagem de políticas), mas que decorrem agora, muito mais, dos mecanismos sinalizados anteriormente por Roger Dale, os quais emergem em contexto de globalização vinculados muito fortemente às transformações socioeconômicas, tecendo e intensificando novas relações entre o nacional e o global.

\section{A SEGUNDA FASE DO ESTADO-AVALIADOR}

Nos anos de 1990, com a presença crescente e incontornável no campo educacional de organizações internacionais como a OCDE, entramos numa nova fase de desenvolvimento do Estado-avaliador. Várias dezenas de Estados, independentemente das suas orientações político-ideológicas e, em grande medida, acima delas, participam ou interferem ativamente, de formas diversas, na construção de um sistema de indicadores e de avaliação comparada internacional em larga escala cujas consequências, mais imediatas, permitem legitimar muitos discursos e vincular muitas políticas nacionais para a educação e formação. Como escrevi noutra ocasião:

Radicando, com mediações mais ou menos evidentes, nas tendências hegemónicas decorrentes de uma agenda global mais ampla, a que não é indiferente o papel das organizações internacionais e supranacionais, o facto é que, nas últimas duas décadas e meia, pelo menos nos países capitalistas ocidentais, as políticas de avaliação foram ganhando um carácter relativamente indiferente às concepções político-ideológicas de diversos governos, alcançando, em decorrência disso, uma certa imunidade ou indiferença às realidades e especificidades nacionais em que os diferentes dispositivos avaliativos se têm instalado e desenvolvido. É, aliás, esta aparente consensualidade que vem ampliando a eficácia legitimadora da avaliação e tornando mais difícil desocultar a sua propalada cientificidade e pretendida neutralidade (ética, política, social...). (Afonso, 2008, p. 14)

Se convocarmos aqui a teoria da neomodernização, pode dizer-se que a OCDE é o mais recente exemplo da existência de um epicentro móvel (para usar a expressão de Piotr Sztompka), uma vez que esta organização fez deslocar os anteriores lugares e atores de referência no que diz respeito à educação e à avaliação internacional.

Desde os anos de 1950, quando surgem os primeiros projetos internacionais comparativos para avaliar os conhecimentos dos alunos de vários sistemas educativos, tem vindo a ser acumulada uma significativa experiência nesse campo de estudos, ao ponto de poder afirmar-se que "a avaliação dos alunos em grande escala, internacionalmente, constituiu uma especialização em si mesma, um campo científico inteiramente estruturado, com as 
suas regras de funcionamento, de legitimação, de controle e de reconhecimento"(Bottani, 2006, p. 77, tradução minha).

Todavia, como refere ainda este último autor, o fim do monopólio de algumas décadas da International Association for the Evaluation of Educational Achievement (IEA), no planejamento e realização de estudos internacionais comparativos relativos à avaliação de desempenho dos alunos, não foi de todo pacífico, sobretudo quando, a partir de finais dos anos de 1980, os EUA tentaram substituir a ação desta agência por outra, ou quando, posteriormente goradas essas intenções, modificaram as relações, apoios e expectativas que tinham mantido com a IEA, tentando subordiná-la ainda mais aos seus interesses e levando a que esta organização perdesse a sua autonomia científica com repercussões na credibilidade da sua ação ante os restantes países. Em consequência deste e doutros fatos, embora inscrevendo-se na continuidade de uma linha de estudos e projetos internacionais comparativos relativos à avaliação do desempenho dos alunos - desenvolvidos de forma mais sistemática a partir da década de 1950 pela IEA (e antecedidos de outras iniciativas e reuniões científicas na área da educação, que chegaram a contar com apoio da UNESCO) -, a verdade é que a entrada em cena da OCDE, já nos anos de 1990, abre as portas para que "as políticas internacionais de avaliação tomem um novo caminho" (idem, p. 75, tradução minha).

Neste sentido, o Programme for International Student Assessment (PISA) é hoje "um dos principais meios de acção da OCDE no sector educativo"e constitui também um importante "instrumento de regulação baseado no conhecimento"(Carvalho, 2011,p. 11; 15). Também, a propósito deste programa, Estela Costa (2011,p. 4) escreve:

A construção de uma imagem credível por parte da OCDE/PISA surge como um pré-requisito para uma regulação soft bem sucedida, sendo que a atribuição de credibilidade ao PISA, por parte da acção pública, afigura-se como um pré-requisito para que a politização do instrumento se concretize. [Para além disto], os documentos e os eventos têm um relevo especial enquanto mecanismos de coordenação das acções, fixando os actores ao Programa, com base em relações de influência mútua, comprovando tratar-se de um instrumento de regulação multidimensional, que actua, circularmente, por diferentes espaços de regulação (global, nacional e local), envolvendo vários actores, interligados de modo multidireccional.

O PISA é, por isso, um programa com dimensões e implicações complexas e diversas, que merece uma análise cuidada e aprofundada, como mostram, entre nós, muitas das recentes produções acadêmicas (cf., entre outros, Barroso; Afonso, 2011; Carvalho, 2011; CNE, 2010; Costa, 2011). ${ }^{9}$

\section{O COMPARATIVISMO AVALIADOR E A TEORIA DA MODERNIZAÇÃO}

Seria importante procurar explicar por que razão a agenda do comparativismo avaliador se espalhou (e espalha) para tantos outros países, não apenas para países do

9 Também no Brasil são cada vez mais frequentes os trabalhos de pesquisa que têm como objeto o PISA. Para um estudo recente, ver, por exemplo, Soares e Nascimento (2012). 
Norte, mais avançados em termos de consolidação do sistema capitalista, e vanguardas de decisivas transições e reconfigurações no sistema econômico, mas também para os países do Sul, periféricos ou semiperiféricos no contexto mundial, como é o caso de uma grande parte dos países da África subsaariana, da Ásia e da América Latina, onde se situam agora as novas potências emergentes, como o Brasil, a África do Sul, a Índia e a China.

Se o capitalismo é um sistema econômico cujo processo de acumulação decorre, essencialmente, da desigualdade e da exploração (palavras hoje em desuso, ou que se escondem em rotulagens politicamente menos conotadas como a de economia de mercado), e sabendo que "os processos educacionais e os processos sociais mais abrangentes de reprodução estão intimamente ligados"(Mészáros, 2005, p. 25), a amplitude e suposta consensualidade em torno da avaliação - que se traduz, por exemplo, pela crescente procura e adesão a indicadores e sistemas de avaliação comparada internacional, não apenas por parte de países centrais, mas também por parte de países semiperiféricos e periféricos revela que, se quisermos pensar a avaliação em termos de teorias de mudança social, não será de todo descabido revisitar a velha teoria da modernizaçãa $0^{10}$ e a posterior teoria da neomodernização.

A este propósito, a minha perspectiva (aqui provisoriamente enunciada) é a seguinte: certas formas de avaliação comparada (como o PISA) espalham-se mundialmente porque muitos países periféricos e semiperiféricos continuam a perseguir objetivos de modernização, seduzidos por ímpetos de progresso (ou de desenvolvimento) conectáveis com agendas educacionais de países capitalistas centrais ou altamente desenvolvidos (ainda que estas agendas pareçam neutras ou benévolas por serem veiculadas por organizações internacionais prestigiadas como a OCDE). Mais especificamente, é a crença nos postulados das teorias da modernização e da neomodernização (e do efeito-demonstração) que subjaz a esta obsessão e expansão avaliativa, a que adere, talvez acriticamente, uma grande parte dos países do sistema mundial.

A explicação será obviamente outra para o caso da presença nestas avaliações internacionais de países centrais ou altamente desenvolvidos. Para além de outras razões, se estes países não estivessem presentes não haveria comparação dentro da lógica que aqui, provisoriamente, procurei enunciar e sustentar. Para além disso, aliás, tal como Nóvoa (2010, p. 35, tradução minha) mostra para o caso da União Europeia, "a comparação pode entender-se como um mecanismo para legitimar a ingerência $[. .$.$] nos assuntos$ educativos nacionais".

Eu diria mesmo que a ilusão de Fukuyama do fim da história combina bem com esta ideologia da modernização (ressuscitada e, ela própria, modernizada), uma vez que a inculcação nos indivíduos (e governos) da crença de que não há alternativas para além do capitalismo democrático liberal é não só congruente com o a-historicismo vigente nas últimas décadas, como é também congruente com a adoção de orientações políticas, culturais e econômicas que parecem pressupor um único padrão de referência - o dos

10 Aliás, como escreveram há alguns anos dois autores, "Sendo na aparência uma problemática passada, dever-se-á notar que a "teoria da modernização», tal como o conceito de «progresso», é uma permanente «Fénix» renascida"(Figueiredo; Costa, 1986, p. 69). 
países capitalistas centrais e/ou países mais desenvolvidos e competitivos, e supostamente mais cultos e mais educados.

Com efeito, alguns dos postulados da teoria da modernização são implicitamente convocados (e parecem reatualizar-se como ideologia) através dos discursos de muitos governantes. Dito de outro modo, estes discursos sugerem que os mesmos níveis de educação e conhecimento estão, ou são, acessíveis a todos os países, sendo para isso necessário (entre outras estratégias políticas e educacionais) que as avaliações nacionais e internacionais comparadas indiquem (objetivamente) quais os défices a superar e os caminhos a seguir, e, deste modo, se formulem políticas educativas reorientadas (e reorientáveis) em função desse objetivo - que seria, afinal, a suposta concretização do acesso plural e democratizador às benesses da dita (e bendita) sociedade da informação e do conhecimento, com o consequente aumento da competitividade econômica e a elevação dos padrões de vida daí decorrentes.

Mas a falácia da ideologia da modernização esconde, como todas as ideologias, os verdadeiros desígnios do capitalismo, também no campo da educação. Como muito bem chama a atenção Immanuel Wallerstein (2004, p. 116, tradução minha), "não vivemos num mundo que se moderniza, mas antes num mundo capitalista. O que faz este mundo mover-se não é a necessidade de progresso mas antes a necessidade de lucro". E acrescenta este mesmo autor:

Nem o Reino Unido, nem os EUA são exemplos para nada em termos de futuro. São apenas estruturas parciais que operam no seio do sistema-mundo singular, que evolui como sempre evoluiu. O que menos necessitamos é de efetuar medições comparativas de entidades não comparáveis nem autônomas, quando o sistema social em que todos vivemos é, pela primeira vez na história humana, uma única unidade na qual todo o jogo se resume a relações internas ao sistema-mundo capitalista. (idem, ibidem, tradução minha)

Do meu ponto de vista, não podemos, portanto, contornar (ou sequer abstrair) os interesses do capitalismo, cujos pilares estruturantes assentam na desigualdade, quando se trata de perceber o que está de fato subjacente às lógicas de uniformização e estandardização cultural e científica, que acabam por acontecer, ou são fortemente induzidas, em decorrência da centralidade das avaliações internacionais comparadas, das quais o PISA é hoje, certamente, o exemplo paradigmático.

Apesar disso, a ideologia da modernização pode ser um indutor eficaz da adesão incondicional de um número crescente de países a formas de avaliação (aparentemente benévolas) que, depois de homogeneizarem para comparar, acabam por justificar as desigualdades, na base dessa mesma comparação, entre países com estatutos profundamente diferenciados no mesmo sistema mundial. Estamos efetivamente em presença de "fenómenos simultâneos e contraditórios de convergência sistémica e de divergência competitiva" (Lima,2011, p. 72) que, do meu ponto de vista, mantêm assim os pressupostos essenciais do sistema capitalista. E, como acrescenta ainda Licínio Lima (idem, p. 76):

[...] se a avaliação visa em primeiro lugar o reconhecimento das diferenças, ou dos «desvios», a partir dos quais se constrói um sistema competitivo e hierarquizado, é indispensável garantir que os objetos em comparação sejam efetivamente compará- 
veis, ou seja, que a comparação seja considerada legítima e que faça sentido para os intervenientes. Por isso, um mínimo de convergência sistémica é exigível para a construção de um sistema de avaliação, integrando nele as unidades a ser avaliadas, para que, seguidamente, se possa transitar da convergência normativa para a divergência competitiva e diferenciadora. Convergir para divergir $[\ldots] .^{11}$

Quadro 1 - Comparação das diferentes fases do Estado-avaliador

\begin{tabular}{|c|c|c|}
\hline $\begin{array}{l}\text { Estado-avaliador } \\
\left(1^{\text {a }} \text { fase, anos de }\right. \\
1980 / 1990)\end{array}$ & $\begin{array}{c}\text { Estado-avaliador } \\
\left(2^{\text {a }} \text { fase, final dos anos de }\right. \\
1990 \text { e atuais anos } 2000 . .)\end{array}$ & $\begin{array}{l}\text { Pós-Estado-avaliador } \\
\text { (antevisão com base em } \\
\text { alquns indicadores) }\end{array}$ \\
\hline $\begin{array}{l}\text { Expressiva autonomia relativa } \\
\text { do Estado-nação na definição } \\
\text { de políticas públicas. Prioridade } \\
\text { ao controle social por parte } \\
\text { do Estado. Estreita vinculação } \\
\text { ideológica neoliberal e } \\
\text { neoconservadora com as políticas } \\
\text { avaliativas e de accountability. } \\
\text { Incremento de avaliações } \\
\text { externas nacionais em larga } \\
\text { escala (provas de aferição, exames } \\
\text { nacionais, exames estaduais...). } \\
\text { Maior incidência nos níveis } \\
\text { de ensino básico e secundário } \\
\text { (fundamental e médio). } \\
\text { Participação não sistemática } \\
\text { em avaliações comparativas } \\
\text { internacionais. Emergência de } \\
\text { formas de avaliação externa } \\
\text { do ensino superior em muitos } \\
\text { países sem essa tradiçã̃o. } \\
\text { Empréstimo e aprendizagem } \\
\text { como principais mecanismos } \\
\text { de transferência de políticas, } \\
\text { nomeadamente no que diz } \\
\text { respeito a países centro-europeus } \\
\text { e norte-americanos, estando, } \\
\text { no entanto, mais presentes os } \\
\text { mecanismos de imposição para } \\
\text { países do Sul onde o Fundo } \\
\text { Monetário Internacional (FMI)/ } \\
\text { Banco Mundial e o "Consenso } \\
\text { de Washington" têm sido } \\
\text { mais precoces e ortodoxos. }\end{array}$ & $\begin{array}{l}\text { Retração crescente da autonomia } \\
\text { relativa do Estado-nação e maior } \\
\text { protagonismo de instâncias } \\
\text { internacionais e transnacionais } \\
\text { (União Europeia, OCDE, Banco } \\
\text { Mundial...). Prioridade do Estado } \\
\text { ao processo de acumulação. Expansão } \\
\text { dos processos de globalização } \\
\text { (cultural, política e econômica...). } \\
\text { Consenso transideológico em relação } \\
\text { à necessidade de políticas de avaliação. } \\
\text { Incidência nos níveis de ensino básico } \\
\text { e secundário (fundamental e médio) } \\
\text { e maior diversificação e precocidade } \\
\text { das avaliações externas nacionais. } \\
\text { Consolidação de agências autônomas } \\
\text { ou de direito privado para a avaliação } \\
\text { e acreditação do ensino superior } \\
\text { nacional. Protagonismo de agências } \\
\text { internacionais para a qualidade, como } \\
\text { a European Association for Quality } \\
\text { Assurance in Higher Education } \\
\text { (ENQA) em contexto europeu. } \\
\text { Regulação pelo conhecimento, definição } \\
\text { de indicadores e adesão a políticas } \\
\text { baseadas em resultados e evidências. } \\
\text { Participação mais frequente e } \\
\text { regular em avaliações comparativas } \\
\text { internacionais, com indução de } \\
\text { rankingss (PISA da OCDE, por } \\
\text { exemplo). Harmonização, disseminaçãa, } \\
\text { estandardização, impposição, entre } \\
\text { outros, como mecanismos de } \\
\text { transferência de políticas. }\end{array}$ & $\begin{array}{l}\text { Estado-nação crescentemente } \\
\text { inserido em contraditórios } \\
\text { processos de governance e } \\
\text { confrontado com a crise de } \\
\text { regulação da economia mundial, } \\
\text { paralelamente à emergência de } \\
\text { uma sociedade civil mundial (que } \\
\text { poderá ser mais afirmativamente } \\
\text { contra-hegemônica face àquelas } \\
\text { agendas). Manutenção do ensino } \\
\text { básico público e universal como } \\
\text { preocupação do Estado-nação, } \\
\text { principalmente em países } \\
\text { periféricos. Exacerbação de } \\
\text { processos de transnacionalização } \\
\text { da educação e aumento da } \\
\text { mercadorização e mercantilização } \\
\text { no âmbito do ensino superior. } \\
\text { Referenciação a acordos da } \\
\text { Organizaça Mundial do } \\
\text { Comércio (OMC) e de outras } \\
\text { organizações similares. Novo } \\
\text { ímpeto do Banco Mundial } \\
\text { na promoção das políticas de } \\
\text { privatização da educação. Expansão } \\
\text { de oferta educativa (superior } \\
\text { e não superior) em regime de } \\
\text { franchising e maior tendência para } \\
\text { a modularização e estandardização } \\
\text { curricular. Ampliação da } \\
\text { privatização dos sistemas e } \\
\text { agências de avaliação e sua conexão } \\
\text { internacional e/ou incremento de } \\
\text { políticas de avaliação comuns no } \\
\text { âmbito de blocos regionais como } \\
\text { a União Europeia ou o Mercado } \\
\text { Comum do Sul (MERCOSUL). }\end{array}$ \\
\hline
\end{tabular}

Fonte: Elaboração do autor.

11 Dito de outro modo, “[... a los países situados muy abajo en la jerarquía del sistema-mundo y a los grupos situados muy abajo en la jerarquía de cada país se les incita a superar el hándicap de su bajo status adoptando esa escala de valores universal. Haciéndose «competitivos» en el mercado, los individuos y los grupos pueden obtener lo que otros ya tienen, y así alcanzarán algún día la igualdad; mientras tanto, la desigualdad resulta inevitable"(Wallerstein, 2004, p. 263). 


\section{A HIPÓTESE DO PÓS-ESTADO-AVALIADOR}

Aliás, esta convergência sistêmica é uma condição sine qua non para a mercadorização/mercantilização global da educação (nas suas diferentes formas); e esta mercadorização/mercantilização global (incentivada nomeadamente pela OMC e pelo Banco Mundial) é também, por sua vez, um novo e importante instrumento de acumulação capitalista, cujas consequências perversas são, em grande parte, imprevisíveis.

Neste sentido, se a lógica do sistema capitalista é a ânsia ilimitada do lucro e da acumulação, é, no mínimo, estranhamente incômodo pensar que os países centrais (ou as organizações internacionais mais poderosas na construção da agenda global) têm um interesse genuíno na subida dos níveis educacionais dos países periféricos e semiperiféricos, a não ser, é claro, quando isso ocorre dentro dos limites que são desejados e necessários para a contínua expansão desse mesmo sistema capitalista mundial, nomeadamente quanto às qualificações exigidas para a mão de obra (que deve ficar disponível enquanto novo exército de reserva qualificado) ou, mais genericamente, como condição para preparar e integrar novos consumidores no mercado mundial.

Nada disto é indiferente ao "imperialismo pós-moderno" no campo cultural, do qual a OMC é um bom exemplo (Jameson, 2001). E é justamente tendo em conta este contexto, de contornos ainda fluidos e incertos, que pode antecipar-se, do meu ponto de vista, a hipótese da emergência de um outro ciclo, que aqui designo, provisoriamente, de pós-Estado-avaliador. Aliás, é também neste contexto que se torna mais pertinente e heurística a perspectiva de Dale (2004) relativa à "agenda globalmente estruturada para a educação". Esta interpretação, entre outros pressupostos, enfatiza a centralidade da economia capitalista no processo de globalização, entende o global como o conjunto de forças econômicas que operam ao nível supranacional e transnacional, e discute os processos que levam à imposição de prioridades por parte de alguns Estados sobre outros. Ao contrário da perspectiva institucionalista (em que os valores e a ideologia que moldam a cultura educacional mundial comum são tão determinantes que se sobrepõem aos fatores nacionais, assim desvalorizando a especificidade destes e o seu contributo), para a perspectiva da agenda globalmente estruturada para a educação o que está em causa é a manutenção e reprodução do sistema econômico capitalista e a posição hegemônica que nele detêm os Estados mais poderosos - o que, no entanto, não impede que sejam analisadas as especificidades dos processos nacionais na procura das suas articulações com as dinâmicas transnacionais e globais.

Estamos a viver um momento histórico que é, em muitos países, de profunda crise econômica, financeira e social, sendo cada vez mais evidentes os sinais que vão no sentido de uma inescrupulosamente obsessiva prioridade ao processo de acumulação-o que, entre outras consequências, tem levado o designado Estado-competidor a rever o que é esperado dos sistemas educativos nacionais.

Sabendo que há vínculos frequentemente convergentes (embora nem sempre claros) entre os interesses do capitalismo e os objetivos de muitas organizações 
internacionais, a ação destas últimas não pode ser pensada aceitando acriticamente os discursos que elas próprias produzem e as missões que anunciam. Neste sentido, podemos e devemos interrogar-nos em relação ao exacerbado (e aparentemente benévolo) protagonismo de organismos internacionais, como a OCDE e o Banco Mundial, que, de forma crescente, são aceitos como inquestionáveis e supostamente imprescindíveis na formulação e estruturação de políticas educativas nacionais.

Aliás, no último caso, e como explica Susan Robertson (2012, p. 299), há uma "estranha não morte do neoliberalismo nas políticas e programações para a educação entre os grupos do Banco Mundial”. Por isso, “o neoliberalismo, enquanto projeto político, apesar dos seus evidentes fracassos no setor de desenvolvimento da educação, ao menos por ora parece incentivar novas levas de invenção neoliberal" (idem, p. 295).

Entre muitos outros fatos que ocorrem nos bastidores destas decisões, pode, por exemplo, haver interesse em compreender o paradoxo (aparente ou não) que resulta da situação de muitos Estados (crescentemente endividados) continuarem a financiar organizações internacionais, nomeadamente quando participam em programas como o PISA da OCDE - desconhecendo-se, apesar disso, qual o papel e impacto que esses mesmos Estados têm (e quais são os que participam verdadeiramente) na definição das agendas que as organizações internacionais disseminam, dado que estas não são de modo algum indiferentes à persistência das estratégias de privatização e de desmantelamento da educação pública estatal. Para além disso,

[...] uma questão igualmente importante é como o Estado administra as contradições cada vez mais profundas entre a educação enquanto direito humano, bem público, commodity vendável e mecanismo de coesão social, e a crise da regulação que agora toma conta da economia política mundial. (idem, p. 293)

A terceira fase, que designei de pós-Estado-avaliador, quer justamente acentuar a ideia de que, para muito além das agendas nacionais e dos efeitos externos da globalização sobre os diferentes países, o que está em curso é uma estratégia de exacerbação e diversificação de lógicas neoliberais de transnacionalização da educação, com ênfase na privatização, mercadorização e mercantilização (Santos, 2004). Determinadas políticas de avaliação e de acreditação, sobretudo no âmbito do ensino superior (Correia, 2010; Stubrin, 2005), poderão mesmo, do meu ponto de vista, aprofundar e ampliar algumas etapas anteriores do Estado-avaliador. Já designadas, aliás, como "políticas de avaliação imperialistas", elas traduzem justamente a ideia de que "há um novo imperialismo a se disseminar através de processos regulatórios de avaliação e acreditação" (Leite; Genro, 2012, p. 84-85). Esta etapa pós-Estado-avaliador referencia-se, não exclusiva, mas principalmente, ao ensino superior e não significa, antes pelo contrário, que a avaliação saia da ordem do dia, mas, antes, que fugirá cada vez mais do âmbito do Estado nacional (sobretudo em países periféricos e semiperiféricos), como, aliás, começou a ser mais evidente já na segunda fase do Estado-avaliador. 
Assim sendo, alicerçadas numa forte consciência crítica nacional e cosmopolita, as alternativas que, neste momento, são possíveis imaginar passam, entre outras, por uma resistência dos Estados-nacionais a estas agendas (sobretudo os que, no sistema mundial, têm menos poder de participar na sua definição), e passam igualmente pelo fortalecimento de novos movimentos sociais contra-hegemônicos que, cada vez mais, procurem construir, de forma mais propositiva e viável, mecanismos para uma efetiva, justa, democrática e transparente regulação internacional do capitalismo, impedindo, desde logo, que o capitalismo acadêmico alastre definitivamente para o campo da educação.

\section{REFERÊNCIAS}

Afonso, Almerindo J. Políticas educativas e avaliação educacional. Braga: Universidade do Minho, 1998.

. Estado, mercado, comunidade e avaliação. Esboço para uma rearticulação crítica. Educação E̋ Sociedade, Campinas: CEDES, v. 20, n. 69, p. 139-164, dez. 1999.

. Estado, globalização e políticas educacionais: elementos para uma agenda de investigação. Revista Brasileira de Educação, Rio de Janeiro: ANPEd; Campinas: Autores Associados, n. 22, p. 35-46, jan./abr. 2003.

. Para uma crítica da avaliocracia. OPS! Revista de Opinião Socialista, Lisboa, n. 2, p. 14-16, nov. 2008.

. Nem tudo o que conta em educação é mensurável e comparável. Crítica à accountability baseada em testes estandardizados e rankings escolares. Revista Lusófona de Educação, Lisboa: UL, n. 13, p. 13-29, 2009.

. Para uma concetualização alternativa de accountability em educação. Educação E Sociedade, Campinas: CEDES, v. 33, n. 119, p. 471-484, abr.jun. 2012.

Al Gore, Jr. Reinventar a administração pública. Lisboa: Quetzal, 1994.

Antunes, Fátima. A nova ordem educacional. Espaço europeu de educação e aprendizagem ao longo da vida. Coimbra: Almedina, 2008.

Azevedo, Joaquim. Sistema educativo mundial. Ensaio sobre a regulação transnacional da educação. Vila Nova de Gaia: Fundação Manuel Leão, 2007.

BArroso, João. Regulação e desregulação nas políticas educativas: tendências emergentes em estudos de educação comparada. In: . (Org.). A escola pública. Regulação, desregulação, privatização. Porto: Asa, 2003a. p. 19-48.

. Organização e regulação dos ensinos básico e secundário em Portugal: sentidos de uma evolução. Educação Ė Sociedade, Campinas: CEDES, v. 24, n. 82, p. 63-92, abr. 2003b.

.; Afonso, Natércio. Políticas educativas. Mobilização de conhecimento e modos de regulação. Vila Nova de Gaia: Fundação Manuel Leão, 2011.

BЕск, Ulrich. La sociedad del riesgo. Barcelona: Paidós, 1998. 
Bottani, Norberto. La más bella del reino: el mundo de la educación en alerta con la llegada de un príncipe encantador. Revista de Educación, Madrid: Ministerio de Educación, Cultura y Deporte, p. 75-90, 2006. Número extraordinario.

Cardoso, Miriam L. Teorias da modernização e expansão capitalista. In: Congresso Brasileiro de Sociologia, 12., 31 de maio a 3 de junho de 2005, Belo Horizonte. Anais... Belo Horizonte, 2005. Disponível em: <http://www.sbsociologia.com.br/portal/ index.php>. Acesso em: 11 nov. 2012.

Carvalho, Luís M. (Coord.). O espelho do perito. Inquéritos internacionais, conhecimento e política em educação - o caso do PISA. Vila Nova de Gaia: Fundação Manuel Leão, 2011.

Chauí, Marilena. O que é ideologia. 2. ed. São Paulo: Brasiliense, 2001.

Conselho Nacional de Educação (CNE). Impacto das avaliaçôes internacionais nos sistemas educativos. Lisboa: CNE, 2010.

Correia, Manolita. La internacionalización de la industria de la educación: el caso australiano. Calidad en la Educación, Chile: Consejo Nacional de Educación, n. 32, p. 169-204, jul. 2010.

Costa, Estela. O «Programme for International Student Assessment» (PISA) como instrumento de regulação das politicas educativas. 2011. 2 v. Tese (Doutorado em Administração e Política Educacional) - Universidade de Lisboa, Lisboa, 2011.

DALE, Roger. Globalização e educação: demonstrando a existência de uma "cultura educacional mundial comum" ou localizando uma "agenda globalmente estruturada para a educação"? Educação छ' Sociedade, Campinas: CEDES, v. 25, n. 87, p. 423-460, 2004.

. Los efectos de la globalización en la política nacional: un análisis de los mecanismos. In: Bonal, Xavier; Tarabini-Castellani, Aiba; Veger, Antoni (Orgs.). Globalización y educación. Textos fundamentales. Buenos Aires: Miño y Dávila, 2007. p. 87-114.

Eisenstadt, Shmuel. Modernidades múltiplas. Sociologia, Problemas e Práticas, Lisboa: IUL, n. 35, p. 139-163, 2001.

Featherstone, Mike. Cultura de consumo y posmodernismo. Buenos Aires: Amorrortu Editores, 2000.

Figueiredo, António; Costa, Carlos. Do subdesenvolvimento. Vulgatas, rupturas e reconsiderações em torno de um conceito. Porto: Afrontamento, 1986.

Inglehart, Ronald; Welzer, Christian. Modernización, cambio cultural y democracia: la secuencia del desarrollo humano. Madrid: CIS/Siglo XXI, 2006.

Jameson, Fredric. Globalização e estratégia política. In: SAder, Emir (Org.). Contracorrente: o melhor da New Left Review em 2000. São Paulo: Record, 2001. p. 133-158.

Leite, Denise; Genro, Herz. Quo vadis? Avaliação e internacionalização da educação superior na América Latina. In: Leite, Denise; Genro, Herz; Solana, Facundo; Fiori, Vivian; Álvarez Ortega, Raul (Orgs.). Politicas de evaluación universitaria en América 
Latina: perspectivas críticas. Buenos Aires: CLASCO; Instituto de Investigaciones Gino Germani, 2012.p. 15-98.

Lima, Licínio C. Avaliação, competitividade e hiperburocracia. In: Alves, Palmira; De Ketele, Jean-Marie (Orgs.). Do currículo à avaliação, da avaliação ao currículo. Porto: Porto Editora, 2011.p. 71-82.

Machado, Lia P. Alcance e limites das teorias da modernização. Revista de Administração de Empresas, Rio de Janeiro: FGV, v. 10, n. 2, p. 169-192, 1970.

Martins, Angela; ZÁkia, Sandra. A produção científica sobre avaliação educacional e gestão de sistemas e de escolas: o campo da questão entre 2000 e 2008. Ensaio: Avaliação e Políticas Públicas em Educação, Rio de Janeiro: CESGRANRIO, v.20,n. 74, p. 9-26,jan./mar.2012. MÉszáros, István. A educação para além do capital. São Paulo: Boitempo, 2005.

Neave, Guy. On the cultivation of quality, efficiency and enterprise: an overview of recent trends in higher education in Western Europe, 1986-1988. European Journal of Education, Oxford:Wiley-Blackwell, v. 23, n. 1/2, p. 7-23, 1988.

Normand, Romuald. Mercado, performance, accountability. Duas décadas de retórica reaccionária na educação. Revista Lusófona de Educação, Lisboa: UL, v. 11, n. 11, p. 49-76, 2008.

NóvOA, António. La construcción de un espacio educativo europeo: gobernando a través de los datos y la comparación. Revista Española de Educación Comparada, Madrid: UNED, n. 16, p. 23-41, 2010.

Osborne, David; Gaebler, Ted. Reinventing government. How the entrepreneurial spirit is transforming the public sector. New York: Addison-Wesley, 1992.

Ravitch, Diane. Vida e morte do grande sistema escolar americano. Como os testes padronizados e o modelo de mercado ameaçam a educação. Porto Alegre: Sulina, 2011.

Robertson, Susan L. A estranha não morte da privatização neoliberal na Estratégia 2020 para a educação do Banco Mundial. Revista Brasileira de Educação, Rio de Janeiro: ANPEd; Campinas: Autores Associados, v. 17, n. 50, p. 283-302, maio/ago. 2012.

SAntos, Boaventura S. A universidade no século XXI. São Paulo: Cortez, 2004.

Sснміdт, Volker H. Modernidade e diversidade: reflexões sobre a controvérsia entre teoria da modernização e a teoria das múltiplas modernidades. Revista Sociedade e Estado, Brasília: Departamento de Sociologia da UnB, v. 26, n. 2, p. 155-183, 2011.

Schneider, Marilda; Rostirola, Camila; Mozz, Gabriela. Entrevista com a professora doutora Sandra Zákia Sousa: avaliações em larga escala e os desafios da qualidade educacional. Roteiro, Joaçaba: UNOESC, v. 36, n. 2, p. 309-314, 2011.

Soares, Sergei; Nascimento, Paulo. Evolução do desempenho cognitivo dos jovens brasileiros no PISA. Cadernos de Pesquisa, São Paulo: Fundação Carlos Chagas; Campinas: Autores Associados, v. 42, n. 145, p. 68-87, jan./abr. 2012.

Stubrin, Adolfo. Los mecanismos nacionales de garantía pública de calidad en el marco de internacionalización de la educación superior. Avaliação, Revista da Rede de Avaliação Institucional da Educação Superior, Campinas, v. 10, n. 4, p. 9-22, dez. 2005. 
SztompкA, Piotr. A sociologia da mudança social. Rio de Janeiro: Civilização Brasileira, 2005.

Teodoro, António. Organizações internacionais e políticas educativas nacionais: a emergência de novas formas de regulação transnacional, ou uma globalização de baixa intensidade. In: Stoer, Stephen R.; Cortesão, Luiza; Correia, J. Alberto (Orgs.). Transnacionalização da educação. Da crise da educação à "educação" da crise. Porto: Afrontamento, 2001. p. 125-161.

. Globalização e educação. Políticas educacionais e novos modos de governação. Porto: Afrontamento, 2003.

Mandato e legitimação nas políticas para a educação. Entrevista concedida a Olinda Evangelista. Perspectiva, Florianópolis: UFSC, v. 23, n. 1, p. 223-234, jan./jul. 2005.

Therborn, Göran. "Modernization" discourses, their limitations, and their alternatives. In: Schelkle, Waltrand; Krauth, Wolf-Hagan; Kohli, Martin; Elwert, Georg (Eds.). Paradigms of social change: modernization, development, transformation, evolution. Frankfurt: Campus and St. Martin's Press, 2000. p. 48-72.

Wallerstein, Immanuel. Capitalismo histórico y movimientos anti sistémicos. Un análisis de sistemas-mundo. Madrid: Akal, 2004.

ZÁkia, Sandra; Arcas, Paulo. Implicações da avaliação em larga escala no currículo: revelações de escolas estaduais de São Paulo. Educação: Teoria e Prática, Rio Claro: UNESP, v. 20, n. 35, p. 181-199, jul./dez. 2010.

.; Oliveira, Romualdo. Sistemas estaduais de avaliação: uso dos resultados, implicações e tendências. Cadernos de Pesquisa, São Paulo: Fundação Carlos Chagas; Campinas: Autores Associados, v. 40, n. 141, p. 793-822, set./dez. 2010.

\section{SOBRE O AUTOR}

Almerindo Janela Afonso é doutor em sociologia da educação pela Universidade do Minho e membro do Centro de Investigação em Educação (CIED).

E-mail: ajafonso@ie.uminho.pt

Recebido em novembro de 2012

Aprovado em dezembro de 2012 


\section{RESUMOS/ABSTRACTS/RESUMENS}

\section{ALMERINDO JANELA AFONSO}

\section{Mudanças no Estado-avaliador: comparativismo internacional e teoria da modernização revisitada}

Depois de rever algumas características da primeira fase do Estado-avaliador, o exercício delineado neste texto começa por revisitar brevemente a (velha) teoria da modernização para, em seguida, sugerir que alguns dos seus pressupostos continuam, em grande medida, a estar subjacentes ao atual comparativismo internacional avaliador que se tem vindo a constituir como agenda política, crescentemente dominante, pelo menos, desde os finais dos anos de 1990, e à qual corresponde o que o autor designa de segunda fase (ou reconfiguração) do Estado-avaliador. $\mathrm{O}$ artigo procura ainda levantar algumas questões e hipóteses em torno de uma terceira fase (a fase pós-Estado-avaliador), a qual, apresentando ainda contornos pouco definidos, pode vir a inscrever-se, com crescente evidência, na continuidade da expansão capitalista das políticas de privatização e mercadorização da educação (e da avaliação).

Palavras-chave: teoria da modernização; reconfiguração do Estado-avaliador; avaliação comparada internacional.

Changes in the evaluative State: international comparativism and the theory of modernization revisited

After reviewing some of the features of the first phase of the evaluative State, the practice outlined in this article starts by briefly revisiting the (old) modernization theory before suggesting that some of its assumptions continue to a large extent to underlie the current international evaluative comparativism. This has become an increasingly dominant political agenda, at least since the late 1990s. Indeed, such period corresponds to what the author calls the second phase (or reconfiguration) of the evaluative State. The article further seeks to raise some questions and hypotheses about a third phase (the post-evaluative State phase) which, although as yet poorly defined, may become part of the continued capitalist expansion of policies of privatization and commodification of education (and evaluation).

Keywords: modernization theory; reconfiguration of the evaluative State; international comparative evaluation.

Cambios en el Estado evaluador: comparativismo internacional y teoría de la modernización revisitada

Tras analizar algunas características de la primera fase del Estado evaluador, el ejercicio planteado en este texto comienza repasando brevemente la (vieja) teoría de la modernización para, a continuación, sugerir que algunos de sus presupuestossiguen, en gran medida, subyacentes en el actual 
comparativismo internacional evaluador que se ha constituido como agenda política, cada vez más dominante, por lo menos, desde finales de los años noventa del siglo pasado, y a la que corresponde lo que el autor denomina segunda fase (o reconfiguración) del Estado evaluador. El artículo también intenta plantear algunas cuestiones e hipótesis sobre una tercera fase (la fase posterior al Estado evaluador), que, aunque todavía presenta unos límites poco definidos, puede inscribirse, de forma cada vez más evidente, en la continuidad de la expansión capitalista de las politicas de privatización y mercantilización de la educación (y de la evaluación).

Palabras clave: teoría de la modernización; reconfiguración del Estado evaluador; evaluación comparada internacional. 